\title{
Democracy, innovation, and the information society
}

\author{
Stefano Rodotà \\ Graduated in Law \\ University of Rome "La Sapienza" \\ s.rodota@tiscali.it
}

\begin{abstract}
We are now rethinking the idea of electronic democracy. Today nobody is looking at e-democracy from the perspective of a living room, push button, instant referenda democracy. In the electronic age it is more and more evident that we are facing a complex evolution of the functioning of political systems - that democracy is becoming not direct, but continuous; that we can look at an extreme democracy. At the same time, we are making a distinction between e-government and e-democracy. Talking about e-government we are looking mainly at the efficiency of the administration. Talking about edemocracy we are looking mainly at the citizens' participation in the political and democratic process. But in the search for efficiency citizens should not be equated merely to consumers. The Internet, or the cyberspace, must remain available to allow free development of personality, the exercise of freedom of speech and associations carrying out civic initiatives, experimenting with all new forms of democracy. Furthermore we can easily see that we are promised a future full of administrative efficiency and consequently more rich in democracy. But at the same time we are too often obscuring a present where growing forms of control and social selection are dramatically limiting individual and collective rights - and mainly through electronic technologies. We cannot accept a kind of institutional schizophrenia. We cannot build up two non-communicating worlds giving people the illusion they are living in a place where they are experiencing technologies of freedom when they are more and more victims of technologies of control. If we look at the information and communication technologies in the framework of the democratic state, we cannot accept the silent transformation of our society in surveillance societies. We have to look to democracy as a process and to the Internet as the new crucial public sphere, a commons for interaction, for the production of public discourse, for the creation of an "espace citoyen", a place for citizenship. We must avoid the transformation of the global agora to a global panopticon, and make available for all citizens a "social software" that can give them the opportunity to be actors of a knowledge controlparticipation-deliberation democratic process, and not voices to be heard only at the end of this process, transforming democracy into electronic populism.
\end{abstract}

Keywords: e-democracy, social software, agora, espace citoyen.

Please use the following format when ciling this chapter:

Rodola, S., 2007, in IFIP International Federation for Infonnation Processing, Volume 233, The Information Society: Innovations, Legitimacy, Eithics and Democracy, eds. P. Goujon, Lavelle, S., Duquenoy, P., Kimppa, K., Laurent, V., (Boston: Springer), pp. 17-26. 
The old electronic democracy has disappeared without ever having been born. Today, for instance, nobody could propose an Electronic Congress, empowering all United States citizens to decide and legislate at the place of the member of the historical Congress as a republican leader Newt Gingrich, did ten years ago in his "Contract for America", supported by people like Alvin Toffler. The idea of allpervasive electronic referenda, of a push-button or living room democracy is no more a part of the agenda in respect of the discussions around democracy and information and communication technologies (ICT).

At the same time, the promise and the perspective of a technological renewal of democracy is still alive. References to net or cyberdemocracy, network society, emergent and extreme democracy make apparent how deep the impact on the political and social debate is. What has changed during the last years?

We have realized that we are dealing with a new public space where the democratic process can be developed, and not simply the substitution of the representative democracy by a direct one: so, electronic democracy cannot be regarded only as a new tool in an ancient, unmodified context. We realized that the immediate impact of electronic democracy can be experimented at the local level, in the 'democratie de proximite', better than in a wider, national one. We have realized that participation and control can be more important than simple deliberation. We have gained a deeper awareness of the risks of a transformation of electronic democracy into the political form of modern populism, of a new plebiscitarian democracy. In trying to describe this change, some scholars say that we have passed from teledemocracy to cyberdemocracy. Going beyond the definitions, the change also reflects the rise of computer networks, making possible many-to-many not just one-to-many communications.

Times are changing, democracy too. In countries like the United States and Europe following the times of the 'democracy of the elites' followed by the mass democracy of the past century, are we entering the new era of the democracy of the public made possible by the information and communication technologies? Is Athens coming back? A strange mix of new possibilities and models is before us. It is not surprising that the information society is regarded as the moment in which the political systems could reach something that over centuries has been considered as the highest democratic idea: Athens direct democracy, a model of citizen participation. At the same time, however, the new technologies are regarded as the means that can make possible a fragmentation of the society, as the forum closer to the logic of political populism or to the negative utopia of the society of total control. Is the actual perspective - that of Orwell - in Athens?

In any case, what is actually happening must be analyzed more carefully, if we would like to have a more precise indication about what kind of society is now emerging. I would like to stay one more minute in Greece. Why are many political scientists looking at the Athenian model? In fact, maybe the Sparta model is more close to some forums of political communication and participation. In ancient Sparta the members of the council, the city government, were elected in this way: Candidates passed one after the other in front of the assembly in the order determined by the drawing of lots. The order in which the candidates passed was not known to the group of impartial evaluators who were sat in a separate room with writing tablets and who could not see the candidates. The evaluators' job was simply 
to assess the loudness of the cheering that each candidate received when he walked in front of the assembly. The candidate receiving the loudest shout and applause was deemed the winner. This model was very far from the open and rational debate of the Athenian institution. Maybe it looks like the 'applaudometer' of some TV shows or the reaction determined by some polls. Can we escape this model?

Many scholars are describing the functioning of political systems by making reference to the words used in the Internet. You can find many books with titles like "republic.com", "vote.com", "governance.com". But at the same time we can confront ourselves with more analytical approaches to the problems and challenges of democracy in the electronic age. In the great majority of debates the perspective of the political system in the age of information and communication technologies are analyzed with regard to the possibilities of a new, richer, direct democracy. This approach reflects in some ways ideas and models which do not correspond to the framework that these technologies are building. In fact the crucial point today is not the conflict between direct and representative democracy or the research of their possible integration. Citizens do not elect a parliament every day, nor were they convened in Athens agora every day. What we are facing now is the passage from an intermittent to a continuous democracy, others say to an endless democracy, in which the voice of the people could be heard in every moment and passive citizens could be changed to active ones. To explain this change the correct reference maybe is not to Athens or Aristotle but to Jean-Jacques Rousseau and James Bryce. In the social contract Rousseau said that English citizens were free on the Election Day and slaves at all other times. How to fill this gap and have citizens instead of slaves in the times between elections has been until now one of the greatest problems of modern democracy. James Bryce in his "American Commonwealth" noted that the political system of the United States was marching towards a stage where "this way of public opinion would become more complete because more continuous".

The model of a "continuous democracy" is before us in many developed countries. But it is what will happen everywhere in the world, maybe very quickly: people can meet continuously in cyberspace; citizens can continuously access a tremendous amount of information; polls give continuous opportunities to be heard (or manipulated); electors can continuously pressure their representatives; the perspective of instant referenda implies the possibility of continuous consultation. Information and communication technologies make it possible. Some landmarks of the democratic process, election first, have already changed their meaning. What are the actual effects of these changes? Are citizens more powerful or only more manipulated and controlled? Is their voice becoming stronger or they are considered more and more only as numbered voices?

Let me start from the distinction between e-government and e-democracy, even if it is not always possible to place some facts only within the framework of either the former or the latter. When talking about e-government we are referring mainly to the efficiency of the administration. When talking about e-democracy we are looking mainly at the citizens' participation in the political and democratic process. But this distinction must be analysed more deeply, starting from two initial remarks.

First. Those citizens are equated merely to 'consumers' in the search for efficiency is to be prevented. We must prevent that the logic of the network society will be entirely captured by the logic of the market. Many of the techniques used in 
the political and administrative process are coming from the business market. A modus operandi should be found in order to prevent the network society from being progressively identified with the commercial environment in which only the rights related to the exchange of goods and services are recognized. What has been defined as the soft new totalitarianism of consumerism is to be prevented. So that citizens are not equated merely to consumers, the new citizenship should not be measured through management criteria like "consumer satisfaction". The Internet and its transformations - cyberspace - must remain available to allow the free development of personality, the exercise of freedom of speech and associations carrying out civic initiatives, and experimenting in all new forms of democracy.

Second. We can easily see that we are promised a future full of administrative efficiency and consequently more rich in democracy. But at the same time we are too often obscuring a present where there are growing forms of control, social sorting and social selection that dramatically limit individual and collective rights, mainly through electronic technologies. We cannot accept a kind of institutional schizophrenia. We cannot build up two separate worlds giving people the illusion they are living in a world where they are experiencing technologies of freedom when they are more and more victims of control technologies. A two-speed democracy could become a tragic caricature of democracy.

If we look at information and communication technologies in the framework of the democratic state should we accept the silent transformation of our society in surveillance societies? The birth of what has been called a naked crowd, the transition towards a nation under suspicion changes all citizens to 'suspects' through the all-pervasive and intrusive technologies of control. It is happening under the pressure of terrorism, but this argument is also exploited for improving other forms of control in the interest of the business community - for instance for fighting piracy in the Internet. But can we fight terrorism by changing the very nature of our societies? How can we work towards having a counterbalance between security and rights and freedoms?

In many international documents, such as the European Convention on Human Rights and the Charter of Fundamental Rights of the European Union, the legitimacy of the limitations of rights and liberties is grounded on the respect of the democratic nature of the states. That is today the most important issue to be discussed when we are looking to e-democracy because of the growing use of electronic devices for controlling, selecting and discriminating between people. This is the first and essential test of compatibility between technology and democracy. So we cannot accept the interpretation given by some United States scholars that the passage from a surveillance aimed to control some specific suspected or dangerous people to a mass control implies a democratization of the system in that the move from a selective control into a universal one improves equality among citizens. That is a paradoxical conclusion. Equality towards the state could now be grounded on the end of all guaranties.

To better understand these trends, it is useful to quote something Tony Blair said two years ago, when he announced that all dangerous people in the United Kingdom could be tagged and tracked continuously via an electronic bracelet, radio frequency technology, microchips under the skin, even after they have left prison. This could be considered only in the context of an announcement, and difficult to be transformed 
in actual practices in the short run, but it reveals a cultural change. And looking always to what is happening in the United Kingdom, we encounter the cases of employees required to carry a small "wearable computer", which allows the employer to guide their activities via satellite, direct them to the goods to collect, specify the routes to be followed or the work to be done, monitor all their movements and thereby locate them at all times. In a report published in 2005 by Professor Michael Blackmore from Durham University, commissioned by the English GMB trade union, it was pointed out that his system already concerned ten thousand people and had transformed workplaces into "battery farms" by setting the stage for "prison surveillance". We are facing a small-scale Panopticon, the harbinger of the possibility for these types of social surveillance to become increasingly widespread. Similar results, although concerning only location at the workplace, are already possible by means of the insertion of a RFID (Radio Frequency Identification) chip in employees' badges.

We are confronted with changes that have to do with the anthropological features of individuals. We are confronted with a stepwise progression: from being "scrutinised" by means of video surveillance and biometric technologies, individuals can be "modified" via the insertion of chips or "smart" tags in a context that is increasingly turning us into "networked persons" - persons who are permanently on the net, configured little by little in order to transmit and receive signals that allow tracking and profiling movements, habits, contacts, and thereby modify the meaning and contents of individuals' autonomy and, consequently, altering the fundamental features of a democratic system.

It becomes apparent that we cannot approach the relationship between technology and democracy by only looking at the deliberative process, at the organization of the public bodies, at the same opportunities given citizens to participate. Democracy is, at the same time, a process and a context, where the basic features of citizenship are defined.

We have to follow an analytical and multilevel approach not only for reconciling technology and democracy, but for understanding better the ways and means that could make e-democracy Possible. Democracy is more and more connected, first of all, with access issues. Access to information means not only the openness of the administration, but also more and more the creation of knowledge commons, grounded for instance on free software, open source, new ideas of copyright, which can improve the future of ideas in the new electronic environment. This is essential, because the democratic debate needs a free and continuous production and confrontation of ideas. In this perspective, access also means the possibility of the diffusion of ideas through free access to the Internet, the possibility of anonymity on the Web, and the absence of censorship. As Cass Sunstein has pointed out "people should be exposed to materials that they would not have chosen in atvance".

But in the global world all totalitarian states are interested in controlling access to, and use of, the Internet, as China has shown in recent times with the cooperation of Yahoo! and Google. So electronic democracy means cyber rights for all citizens, grounded in a new global Bill of Rights, as has been proposed at the United Nations World Summit on Information Society in Tunis (November 2005), in a Global Internet Freedom Act, such as that introduced in the United States Congress by the congressman Chris Cox. 
These are some essential pre-conditions for a democratic functioning of cyberspace and for making citizens' participation in the political process effective. It means not only giving people the opportunity to interact with politicians. It needs the consideration of cyberspace as a truly real public sphere. But it raises some problems. I would like to quote an interview by Howard Dean, one of the candidates in the last presidential primaries in the US, who experienced an extensive use of information and communications technologies in his electoral campaign. The interview was published by the review magazine "Wired" under the title "How the Internet invented Dean" What did Dean say? I quote: "If I give a speech and if the blog people don't like it, next time I change the speech". It has been said, and it is still said, that candidates are more or less created by television, at least in the sense that they must be accepted by their capability to use television communication. Now we could say, as the title of the interview of "Wired" indicated, that we are entering the era where candidates are created also by the Internet. But through Dean's words we can look at some new and also worrying aspects of the politics in the electronic dimension. Are we facing the birth of a political model where programs and proposal are better tailored to the needs of the citizens or it is a model where technology gives incentives to the search of consent at any price, irrespective of general choices and principles, making politics poorer in the dimension of the search of general interest? When Dean said "I'd change my speech" does it mean that he is taking what the people said seriously, or that he is ready to change his ideas and his capability to give a political indication connected with general interest?

The problem of access to electoral competition gives us another way of looking at the perspectives of electronic democracy. Fund raising through the Internet can make candidates more free and independent from big business: for Dean, but also for John Kerry in the first part of his campaign, funds collected via the Internet were the first source of financing. But Dean's strategy was not primarily aimed at fund raising but to integrate many electronic means - websites, mailing and telephone lists, SMS text messaging, web, television. So Dean had the possibility to directly contact in one month more than 600,000 people - giving a new relevance to the most important meta-network existing in the United States. This meta-network is called "meet-up" regrouping 4,000 communities with $1,200,000$ members, regularly meeting in 700 cities in the US. But these meetings are not just electronic ones. After an initial electronic contact they make possible house meetings, meetings in cafés, bars and other places. Two remarks about this point. First: through millions of contacts there is in fact the transfer in the real world of the logic of the electronic network. Through the electronic network a network has built up where people are not only meeting virtually, but also in the real world. Second: this case shows that new electronic technologies do not imply necessarily a discontinuity. In many cases the improvement of the democratic process can be the result of the encounter of old and new technologies.

Look for instance at Seattle, where the non-global movement was born. That meeting was organized through the Internet. Without the Internet the manifestation could not be possible. But the real event was created when people met in the real places and streets in Seattle, and the images of the people regrouping and meeting in Seattle were transmitted everywhere in the world by an old media, television. That global and very influential event was not only a result of the new technologies, of the 
electronic possibilities offered for the participation of the people, but also of the combined interaction of more traditional ways to meet - places, streets (the agora), the old television technology - and Internet. A mixed reality is emerging through this interaction. So it is apparent that many forces are at work reshaping democracy through information and communication technologies, and that we are facing not substitutive, but cumulative effects.

But if we are interested in improving citizens' participation, we must also promote trust. This means to give them adequate guarantees concerning the respect of the private sphere, looking at data protection not only in the traditional perspective of privacy as the right to be left alone, but as a precondition of the exercise of rights and liberties. If we look at e-government, we must realize that the use of the new electronic opportunities offered to citizens is also a function of the fact that, for instance, their access is not regularly tracked and registered, data retention is strictly limited, principles of finality and proportionality are respected. Otherwise, if citizens are worried about the use of the data collected in connection with their access and with their participation, they could renounce this opportunity, thus making the presence of active citizens in public life poorer and weaker.

It means that e-government is not in itself democratic. It depends on the context. In the absence of strong safeguards for the information concerning them, people are increasingly in danger of being discriminated against because of their opinions, religious belief, or health. Data protection is therefore to be regarded as a key component of the 'equality' society. In the absence of strong safeguards for data concerning political opinions or membership of parties, trade unions or associations, citizens run the risk of being excluded from the democratic process. Never should one forget what happened under totalitarian regimes where deep violation of fundamental rights were made possible exactly by the massive collection of information which allowed continued, pervasive and oppressive surveillance of every day life. From this point of view, data protection must be the ultimate asset and least dispensable component of the society of dignity.

From this perspective, we have to look at democracy as a process and to the Internet as the new crucial public sphere, a commons for interaction, for the production of public discourse, for the creation of an "espace citoyen", a space for citizenship. At the time of the protest everywhere in the world against the United States' intervention in Iraq, the "New York Times" wrote that Internet made possible the birth of a new mobile, global super-power. It means that the Internet must be considered as a constitutional space where the reference values cannot be the technology itself or market-driven forces. We cannot only make reference to a general concept such as the collective mind, in the sense of Levy, or collective intelligence in the sense of De Kerkhove or mobile multitudes that will spontaneously drive our society in a new and active democratic process.

It is true that we are living more and more in a world of networks. But can we conclude that the future will be networks instead of states, a post-democracy near to a "new medievalism"?

If we look at what it is happening in the real world, at China or athe request of the United States government to Google, or to the telephone companies for having all types of data concerning their customers, we can easily see that we must deal with conflicting values and interests and that the solution cannot be found in 
developments driven by the technology itself. The fascinating utopia of the Web as a place of anarchist freedom, that cannot be limited and does not need rules, has been overcome. We are experiencing a situation where the freedom of expression is under attack; traffic data are traced, stored, and transmitted to public bodies; and access to knowledge is restricted in many cases for security or economic interests.

These are the reasons why some scholars, like Benjamin Barber, continue to propose some caveat - that could be considered too pessimistic - but which reflects a situation whereby the Internet can still be considered a dimension through which some democratic needs - prudent judgment, mediation, universality, control by people - are dangerously challenged by a rush towards deliberation, the difficulty of selecting truly relevant issues, the segmentation of society, the privately owned portals.

These problems show that we need not only a careful and continuous costbenefit analysis. Above all, the perception of this kind of problem implies that in the short run the main issue of 'cyberdemocracy' is the production of a "social software".

Once again, a multilevel strategy is needed. We must improve civic networking, where the direct awareness of citizens makes more difficult the populist, plebiscitarian use of technologies. We must improve citizens' access to knowledge and their power of producing and diffusing knowledge. We must look at the protection of the private sphere as an essential condition for autonomy and freedom in the public sphere. Only by providing people with this basic social software is it possible to achieve a strong citizenship, avoiding an outcome whereby popular participation will be converted to an illusion, a slogan without any change in the true deliberation process.

If we reflect on the past, we can easily discover a paradoxical effect of the first approach to electronic democracy issues. Searching for a direct hyperdemocracy, in fact the result was a "democratic reductionism", because the core issue of democracy was identified only with the final stage of the process - deliberation. There was an expansion only of some well known institutional devices - plebiscites, referenda. And the substance of the political process remained up/down.

Entering the horizontal society - the true product of the information and communication technologies - we cannot simply try to substitute a bottom/up or top/down approach. It is for that reason we must look at the social software, with a new distribution of political and social power. Social software applications include, for instance, electronic commons, blogs, content syndication, forum, chats, instant messaging, collaborative editing, deliberative polling (according to the proposal of James Fishkin and Bruce Ackerman), social network platforms, open Internet and maybe public portals like the Quaero project in France (a new version of the public sphere, where the core issue is the reconstruction of the citizenship).

It implies a consideration of local and decentralised initiatives not as a minor version of the whole electronic democracy, but as a starting point of the people's inclusion, initiative and participation. It implies the concept of openness, starting from the reference to software. Open politics must become the key reference for cyberdemocracy, giving people a true and wide range of powers.

The basic concept cannot only be the information society, but must also include a knowledge and participation society. Starting from shared knowledge we can pass 
to organization; from organization to control; from control to initiative; from initiative to participation; and finally to deliberation, deeply transformed by the new institutional context.

Taking this perspective we are neither dealing with a radical discontinuity with the traditional way of working of the democratic, representative systems nor entering an autoreferential dimension of each network. And the relationship between citizens and states will be modified because it is becoming possible to pass, in many cases, from public surveillance it its opposite, what has been called "sousveillance", with citizens keeping watch of public bodies.

New forms of interaction are in front of us: between people of course, but also between new actors, new forms of public action and the traditional democratic institutions. A new face of democracy can be discovered and built up, and it can happen without a complete disintermediation, the end of all forms of the representative democracy that, on the contrary, could be renewed and improved by technology.

We must remember what happened at the time of the birth of Internet, with the enthusiasm for the end of all forms of mediation in accessing knowledge. The reality is a new form of mediation: without Google or Yahoo! access to knowledge would be impossible.

So, we are facing new general problems. Lack of political participation and of communication between the general public and decision makers reveals not only a weakness on the side of society. It also weakens the mediation function of the traditional representative institutions, so producing a functional and structural deficit in the political system. Reopening channels of communication, empowering citizens through new technologies, making possible new forms of social dialogue could reinvent forms and places of mediation: a mediation not excluding but including the direct contribution of people, working together in a new, open, wider public space, where power is continuously distributed and decisions are not the monopoly of a single, separated institution. 